\title{
AOR
}

Selected Papers of \#AolR2021:

The 22nd Annual Conference of the

Association of Internet Researchers

Virtual Event / 13-16 Oct 2021

\section{NEOLIBERAL CARTOGRAPHY: A VISUAL-SEMIOTIC ANALYSIS OF THREE NAVIGATION APPS}

Igal Baum

Department of Communication, University of Haifa

Rivka Ribak

Department of Communication, University of Haifa

The proposed presentation adopts visual-semiotic tools to analyze the virtual environment conjured by navigation apps. Recent work has pointed to the complicated relationship between maps and the spaces they purportedly depict (Crampton, 2001; Farman, 2010; Kitchin \& Dodge, 2007), interpreting maps as simulacra that are intimately intertwined in the ideology and design of gaming (Lammes, 2017; Lammes \& Wilmott, 2018). In the paper, we develop a semiotic walkthrough method that allows us to identify four representational practices of these widely-used navigation apps: the map is personalized, commercial, it depicts time and it is reflexive. Our analysis explores the different ways in which these practices, which offer a radical departure from print cartography, materialize the neoliberal reading of individuals' movement in space in terms of value creation (Mirowski, 2015).

The analysis focuses on three apps: Waze, Moovit and Gett. The apps were developed for different types of users and thus with different conceptions of movement in space and different revenue models. Waze is directed to car-driver users and is based on ads presented to the drivers according to their location. Moovit focuses on users of public transportation and derives its revenue from municipalities seeking to promote and monitor transportation services. Lastly, Gett is a platform that connects passengers and taxi drivers who pay subscription fees to the company. We were interested in the maps produced by and for these different revenue models and studied them using the Walkthrough method (Light, Burgess \& Duguay, 2018) and a semiotic analysis with a visual emphasis (Van Leeuwen, 2005).

In what follows we briefly discuss the four representational practices we identified:

Suggested Citation (APA): Baum, I. and Ribak, R. (2021, October). Neoliberal cartography: A visual- semiotic analysis of three navigation apps. Paper presented at AolR 2021: The 22nd Annual Conference of the Association of Internet Researchers. Virtual Event: AolR. Retrieved from http://spir.aoir.org. 
The interactive map is personalized - the apps show maps that adopt the perspective of the users and change as they move in space. In Waze, the avatar of the car driver is an arrow that is directed not to the North but to the road ahead of the driver. The avatar is located at the bottom-center of the map, and the road progresses as the avatar moves forward, recalling a driving simulator. The environment is reduced into four information signs - the driver, the road, commercial advertisers, and time - that both indicate and respond to the users' movement in space. In Moovit, users can see their avatars from a satellite point of view, as though they were board game pawns. While Moovit's map seems closer to analogue cartography, it too is personalized in that it shows only the relevant section of the way and responds to rout changes. Gett presents two stages: first, the map represents the space that spans between the user and the taxi; then it collapses the user and the taxi in a realistic depiction of a car top to indicate their joint location on a distant and relatively uninformative map (while the driver typically navigates using Waze).

The map is commercial in that it is informed by the economic model of the app. In Waze the map represents only those roadside businesses that pay to be in included. This is particularly striking in the case of gas stations, which - though seemingly inseparable from the road and the driving experience - appear only in some cases (and years after the app has been in use); but also in the case of large strip malls, which may be represented by the few stores that paid to have their logo appear in the map. Thus public space is translated in the map into a shopping mall and the users are constructed as consumers. Moovit's users have the least agency as they are transported in space. Nonetheless, through their movement, they are generating revenue to the app's third party partners. Finally, Gett's app itself is the site of the actual (though virtual) money transaction that marks the move from the first to the second stage. To facilitate the transaction, the map of the first stage provides constant information on the taxi as it approaches its future customer, in contrast to the map presented in the second stage.

The map offers a visual depiction of time - arguably, time rather than space is its raison d'être. All the maps present a digital clock. In Waze, time to destination determines the rout, and thus the map the users use; and since it is constantly changing, the rout - and the map - may change on the move. Waze also presents a thermometer-like time visualization that appears when traffic slows down, and measures progress in terms of the minutes that go by through the end of the congestion. Moovit users have little control over time but Gett measures two "times" for its users - waiting for the taxi, and being driven by it, each with its respective value. Thus whereas analogue maps represented space and allowed their users to calculate time, digital maps intertwine these two dimensions.

Lastly, the map is reflexive, creating space for and by its different users. Waze incorporates users' data both to regulate their behavior (e.g. speed alerts) and to seemingly subvert surveillance (e.g. police alerts). Isolated, individual users monitor the environment while being monitored (by Moovit), engaging with the brands that appear on (Waze's) map, and rating while being rated by (Gett's taxi) drivers. The users are on the maps that they create and update - the maps that monitor and monetize their movement, require their never-ending input, and incessantly change along with changing business interests. 
In this cartographic regime, map users adopt a "self as business" (Gershon, 2017) logic in which navigation must constantly create value, as the map becomes less a tool for regulating their behavior and more, a tool for producing it (Zuboff, 2019).

\section{References}

Crampton, J. W. (2001). Maps as social constructions: Power, communication and visualization. Progress in Human Geography, 25(2), 235-252.

Gershon, I. (2017). Down and out in the new economy: How people find (or don't find) work today. University of Chicago Press.

Farman, J. (2010). Mapping the digital empire: Google Earth and the process of postmodern cartography. New Media \& Society, 12(6), 869-888.

Kitchin, R., \& Dodge, M. (2007). Rethinking maps. Progress in Human Geography, 31(3), 331-344.

Lammes, S. (2017). Digital mapping interfaces: From immutable mobiles to mutable images. New Media \& Society, 19(7), 1019-1033.

Lammes, S., \& Wilmott, C. (2018). The map as playground: Location-based games as cartographical practices. Convergence, 24(6), 648-665.

Light, B., Burgess, J., \& Duguay, S. (2018). The walkthrough method: An approach to the study of apps. New Media \& Society, 20(3), 881-900.

Mirowski, P. (2015). Defining neoliberalism. In Mirowski, P., \& Plehwe, D., eds., The road from Mont Pèlerin: The making of the neoliberal thought collective, with a new preface. Pp. 417-450. Harvard University Press.

Van Leeuwen, T. (2005). Introducing social semiotics. Psychology Press.

Zuboff, S. (2019). The age of surveillance capitalism: The fight for a human future at the new frontier of power. Profile Books. 